\title{
Practical constraints on atmospheric methane removal
}

\author{
Klaus S. Lackner ${ }^{(0)}$ \\ ARISING FROM R. B. Jackson et al. Nature Sustainability https://doi.org/10.1038/s41893-019-0299-x (2019)
}

In a Comment, Jackson et al. ${ }^{1}$ put forward a process for removing methane from the atmosphere that is analogous to direct air capture of carbon dioxide. To capture methane, the authors propose the use of zeolite sorbents followed by catalytic destruction. The goal is to reduce atmospheric methane concentrations from the current $1,860 \mathrm{ppb}$ to pre-industrial levels of $\sim 750 \mathrm{ppb}$.

Methane removal poses two challenges: extreme dilution and competition from natural processes. This raises the question of whether methane is really the best target for removal from the air.

First, the dilute concentration of methane in the atmosphere challenges economical removal. On a mass basis, methane is currently 600 times more dilute in Earth's atmosphere than carbon dioxide; in pre-industrial times it was 1,000 times more dilute. Even with the remarkably low pressure drop of $80 \mathrm{~Pa}$ and high collection efficiency of $74.5 \%$ postulated by Carbon Engineering for their direct air capture process ${ }^{2}$, the energy requirement for electric fans to filter out a metric ton of carbon dioxide is still $220 \mathrm{MJ}$. (For comparison, $80 \mathrm{~Pa}$ is the pressure fluctuation experienced by a rigid surface exposed to a small wind gust with a speed of $12 \mathrm{~m} \mathrm{~s}^{-1}$ ). An energy bill that is three orders of magnitude larger for a ton of methane would be prohibitive, and it is a good example of how Sherwood's Rule-separation costs tend to scale linearly with dilution-can assert itself $\mathrm{f}^{3-5}$. At $\$ 3 \mathrm{kWh}^{-1}, 220 \mathrm{GJ}$ add US $\$ 1,833$ in cost. For methane, Sherwood’s Rule eliminates fans and blowers as a practical means of moving air through sorbent beds; the amount of air that would need to be moved would simply be too great. However, it does not prohibit passive methods of removing methane. If methane is to be stripped out of the atmosphere, taking advantage of natural air flow provides a viable solution.

Natural processes destroy roughly $10 \%$ of the methane in the atmosphere every year ${ }^{6}$. To substantially enhance natural processes, methane removal units would have to process the entire atmosphere in less than a decade. Unlike carbon dioxide, which accumulates in the atmosphere and lingers for millennia-and for which nobody suggests such an ambitious scale-methane just flows rapidly in and out of the atmospheric reservoir. If the water level in a bathtub with a wide-open drain is rising, turning down the faucet may be a better strategy than bailing. To compensate for unmanageable anthropogenic releases, it may be easier to curtail some natural emissions than to remove methane directly from the atmosphere. Once methane emissions are curbed, concentrations will decline rapidly. This stands in stark contrast to carbon dioxide emissions, which, by lingering, pose a stock (rather than a flow) problem. On the other hand, if climate feedbacks were to cause large methane releases from permafrost ${ }^{7}$, passive collectors at a massive scale may still be the best option available.

However, methane is not the only greenhouse gas with extremely low concentrations. Now that passive designs are opening the door to remediation of extremely low concentrations, the worthiest target for catalytic removal may be long-lived nitrous oxide. Nitrous oxide is another greenhouse gas whose emissions are difficult to avoid but in comparison to methane, its long lifetime greatly reduces the rate at which the atmosphere needs to be processed.

Received: 4 August 2019; Accepted: 21 February 2020;

Published online: 23 March 2020

\section{References}

1. Jackson, R. B., Solomon, E. I., Canadell, J. G., Cargnello, M. \& Field, C. B. Methane removal and atmospheric restoration. Nat. Sustain. 2, 436-438 (2019).

2. Keith, D. W., Holmes, G., St. Angelo, D. \& Heidel, K. A process for capturing $\mathrm{CO}_{2}$ from the atmosphere. Joule 2, 1573-1594 (2018).

3. Sherwood, T. K. Mass Transfer Between Phases: 33rd Annual Priestley Lecture (Phi Lambda Upsilon, Pennsylvania State Univ., 1959).

4. House, K. Z. et al. Economic and energetic analysis of capturing $\mathrm{CO}_{2}$ from ambient air. Proc. Natl Acad. Sci. USA 108, 20428-20433 (2011).

5. Lackner, K. S. et al. The urgency of the development of $\mathrm{CO}_{2}$ capture from ambient air. Proc. Natl Acad. Sci. USA 109, 13156-13162 (2012).

6. Turner, A. J., Frankenberg, C. \& Kort, E. A. Interpreting contemporary trends in atmospheric methane. Proc. Natl Acad. Sci. USA 116, 2805-2813 (2019).

7. Schuur, E. A. G. et al. Climate change and the permafrost carbon feedback. Nature 520, 171-179 (2015).

8. Reay, D. S. et al. Global agriculture and nitrous oxide emissions. Nat. Clim. Change 2, 410-416 (2012).

\section{Competing interests}

K.S.L. is a faculty member at Arizona State University (ASU) and a co-inventor of IP that is owned by ASU and relates to passive removal of carbon dioxide from the atmosphere. He could therefore benefit from the commercialization of passive air contactor systems. ASU has licensed such IP to Silicon Kingdom Holdings Limited (SKHL) and owns a stake in the new company. As employee of the University, K.S.L. advises the company. SKHL plans to support air capture research at ASU and has granted K.S.L. shares for his advisory role.

\section{Additional information}

Supplementary information is available for this paper at https://doi.org/10.1038/ s41893-020-0496-7.

Correspondence and requests for materials should be addressed to K.S.L.

Reprints and permissions information is available at www.nature.com/reprints. Publisher's note Springer Nature remains neutral with regard to jurisdictional claims in published maps and institutional affiliations.

(c) The Author(s), under exclusive licence to Springer Nature Limited 2020 